\title{
IAMOT 2007
}

Presented by University of Miami, Department of I ndustrial Engineering

Home > Papers > Paulo A. Zawislak

Paulo A. Zawislak

\section{R\&D, ENTREPRENEURSHI P AND I NNOVATI ON I N BRAZI L: WHERE IS THE MI SSI NG LI NK?}

\author{
Paulo A. Zawislak \\ PPGA/ UFRGS \\ Cristina Castro-Lucas \\ PPGA/ UnB and Unieuro \\ Eda Souza \\ PPGA/ UnB
}

Full text: Not available

Last modified: December 1, 2006

\section{Abstract}

$R \& D$, entrepreneurship and innovation are surely linked concepts. The general idea is that, to have actual innovative outcomes, R\&D projects should be managed based on pre-existing individual and organizational entrepreneurial culture and attitude. On the one hand, we consider entrepreneurial behavior as the search for both new technological and new commercial venture opportunities. Is the clear acceptance of risk taking, but also the clear expectation of Schumpeterian extraordinary profits. On the other hand, investments on $R \& D$ projects are the very crystallization of deliberate and organized efforts to really reach acknowledged economic results from these new ventures. Firms that work closely to these dimensions should, thus, easily reach innovation and competitiveness. Brazilian reality, however, indicates that this sort of R\&Dentrepreneurship-innovation tripod seems to have some important gap. Very low levels of $R \& D$ expenditures (something around $1 \%$ of GDP over the last decades) coped with an entrepreneurial culture that barely is focused on opening new companies (with no new ventures!) completely blast the expectation on having technological innovation and socio-economic development together. Therefore, where is the missing link? Based on the national science and technology statistics and on a recent field research made over 450 Brazilian businessmen, this paper aims to make some light on one possible explanation for the above mentioned gap. The low level of both R\&D expenditures and innovative outcomes seems to be directly related to the absence of an innovative culture in what one should call "the Brazilian Businessmen DNA". Looking closely, we found that most of Brazilian entrepreneurs are only focused on operational management practices as very drivers for running their business. They surely try to align their business strategy with marketing, operations, financial, or HR strategies. Even more, they work improvising, making gimmicks and praying on a sort of "the Brazilian Way" of behavior. What they rarely do is to align business and innovation strategies. Whenever they create "new business", they make it based on on-going already established and successful ventures, where risks are already known. The result seems to be obvious: to compete they have to lower their prices instead of adding new value to their products and process. This tends to reduce profitability instead of making new profits. Brazilian entrepreneurs, though, work only to make "one business else" then to make "one new business". In this behavioral pattern, innovation is undermined. Without stronger innovative strategic goals, Brazilian companies seem to perceive less importance on increasing their $R \& D$ expenditures. The general result, though, is the very low level of $R \& D$ efforts which leads to very low level of development indicators, such as per capita GDP.

\author{
Research \\ Support Tool \\ For this \\ refereed \\ conference \\ abstract... \\ Capture Cite \\ View Metadata \\ Printer Friendly \\ Context
}

Author Bio

Define Terms

Related Studies

Media Reports

Google Search

Action

Email Author

Email Others

Add to Portfolio

Learn more

about this

publishing

project...

PUBLIC

KNOW

LEDGE 